\title{
EFEKTIFITAS MEJA TPS DALAM MENINGKATKAN PEMAHAMAN OPERASI PENJUMLAHAN, PENGURANGAN DAN PERKALIAN BILANGAN ASLI UNTUK SISWA SD KELAS 2 DAN 3
}

\author{
Magdalia Frisca Madelyn Sitanggang, Hary Nugraha, Ade Suci Ramadhani, \\ Rifda Ulfa Mukhtar \\ Pendidikan Matematika, Universitas Riau \\ Email : magdaliafrisca27@gmail.com
}

\begin{abstract}
The learning activities in the Quantum Education is having problems in learning activities arithmetic operation of calculating natural numbers, this due to mathematics is abstract. So it's very difficult to be understood by students with age range of 7-11 years. Teaching media is learning facilities that can concretize abstract teaching materials. The purpose of this activity is to see the success of TPS Desk as medium of mathematics learning that can improve students' understanding learning material of operations for natural numbers. The method used activity is the design, use and mentoring business bookkeeping. The results of the activities that have been done show that TPS Desk managed to increase students' understanding in learning activities arithmetic operations on natural numbers.
\end{abstract}

Keywords : Media, Abacus, Napier, TPS Desk

\section{PENDAHULUAN}

Matematika merupakan cabang ilmu pengetahuan yang mempunyai peranan penting dalam perkembangan ilmu pengetahuan dan teknologi, baik sebagai alat bantu dalam penerapan-penerapan bidang ilmu lain maupun dalam pengembangan matematika itu sendiri. Penguasaan materi matematika oleh peserta didik menjadi suatu keharusan yang tidak bisa ditawar lagi di dalam penataan nalar dan pengambilan keputusan dalam era persaingan yang semakin kompetitif pada saat ini. Matematika bukanlah ilmu yang hanya berguna untuk di bidang matematika itu sendiri, tetapi ilmu yang juga dapat dimanfaatkan di bidang ilmu lain (Siagian. M. D, 2016). Pendidikan matematika pada hakikatnya mempunyai dua arah pengembangan yaitu untuk memenuhi kebutuhan masa kini dan masa yang akan datang. Purwosusilo mengatakan dalam memenuhi kebutuhan masa kini, pembelajaran matematika dititikberatkan pada pemahaman konsep-konsep dasar agar dapat menyelesaikan masalah matematika dan masalah dalam bidang-bidang yang lain (Juliant dan Noviartati, 2016).

Asep Jihad memberikan batasan bahwa matematika berbeda dengan mata pelajaran lain, hal ini dikarenakan objek pembicaraan dalam matematika adalah abstrak (Rusli, 2018). Oleh karena itu, ketika siswa diminta untuk memahami konsep-konsep dasar matematika yang pada umumnya diajarkan pada tingkat SD kelas 2 dan 3, akan terhambat karena siswa tersebut belum memiliki pengetahuan yang cukup luas untuk dapat memahami objek abstrak dalam matematika ini. Hal ini sejalan dengan kajian psikologis oleh Piaget yang membagi tahap-tahap perkembangan kognitif menjadi empat bagian yaitu pada tahap operasional konkret (usia 7 sampai 11 tahun). Piaget mengatakan bahwa pada tahap ini anak telah memiliki kecakapan berpikir logis namun hanya pada benda-benda yang konkret.

Tidak mempunyai konsep dasar matematika pada tahap operasional konkret mengakibatkan siswa bimbingan belajar Quatum Education kehilangan motivasi belajar karena tidak dapat memahami pembelajaran matematika. Ketidakpahaman ini terjadi terutama pada konsep dasar matematika penjumlahan, pengurangan, dan perkalian pada bilangan asli. Jika konsep dasar yang yang diperlukan bagi siswa itu tidak dimiliki, maka untuk materi berikutnya akan mengalami masalah, karena dalam pembelajaran matematika konsep dasar akan selalu digunakan. Hal inilah yang menyebabkan para tutor di Bimbingan belajar Quatum Education akan mengalami kesulitan untuk melanjutkan materi pembelajaran.

Berdasarkan masalah di atas, maka diperlukan media pembelajaran yang dapat membantu meningkatkan pemahaman siswa 
dalam kegiatan pembelajaran matematika. Hal ini dikarenakan penggunaan media pembelajaran memiliki beberapa manfaat, yaitu sebagai berikut.

1. menyamakan persepsi siswa.

2. mengkonkritkan konsep-konsep yang abstrak.

3. menghadirkan objek-objek yang terlalu berbahaya atau sukar didapat ke dalam lingkungan belajar.

4. menampilkan objek yang terlalu besar atau kecil.

5. memperlihatkan gerakan yang terlalu cepat atau lambat. Dengan menggunakan teknik gerakan lambat (slow motion) dalam media film bisa memperlihatkan tentang lintasan peluru, melesatnya anak panah, atau memperlihatkan suatu ledakan (Shufa, 2016).

Berdasarkan manfaat media pembelajaran tersebut, berarti dengan bantuan media pembelajaran, siswa akan lebih mudah memahami konsep dasar dari matematika. Oleh karena itu, dengan penggunaan media pembelajaran, siswa tidak akan mengalami masalah di materi pembelajaran berikutnya.

Salah satu media yang dapat digunakan pada pembelajaran matematika adalah batang napier. Batang napier ditemukan oleh seorang bangsawan dari skotlandia yaitu John Napier (1550-1617). Pada awalnya batang napier menggunakan prinsip perkalian desimal, atau latitice diagram (arah) dan terdiri dari 10 kotak. Kotak terbatas menunjukkan sebuah bilangan dasar (digit), selanjutnya berturutturut merupakan hasil perkalian bilangan dasar, dimana satuan diletakkan dibagian bawah diagonal, sedangkan bagian puluhan diletakkan di bagian atas diagonal. Batang napier yang saat ini digunakan pada Meja TPS (Tabel Perkalian dan Sempoa) menggunakan prinsip kerja yang sama, dengan jumlah kolom enam dan jumlah baris lima.

Kelebihan media batang napier menurut Rusefendi (Aristiani, 2013) adalah gambarnya bisa dipindahkan dengan mudah sehingga siswa bisa lebih antusias untuk ikut aktif secara fisik dengan cara memindahkan objek angka. Pola mengajarnya bisa memudahkan siswa dalam mengalikan angka karena tersusun dalam bentuk kotak persegi, sehingga membuat anak lebih mudah mengalikan angka yang satu dengan angka yang lain.

Media pembelajaran berikutnya yang dapat digunakan adalah sempoa. Priyani mengemukakan bahwa sempoa (ada juga yang menyebut sipoa, cipoa, swipoa, simsuan, abacus atau sorokan), merupakan alat hitung tradisional seperti yang biasa digunakan di Jepang dan Cina. Berupa kotak segi empat yang dibagi menjadi dua bagian, atas dan bawah dengan manik-manik bernilai satu pada bagian bawah (Syifa, 2015).

Meja TPS (Tabel Perkalian dan Sempoa) juga mengadopsi cara kerja alat hitung sempoa. Meja TPS adalah inovasi baru yang didesain memiliki banyak fungsi, bukan hanya sebagai fasilitas untuk menulis dalam kegiatan pembelajaran sehingga pembelajaran lebih menyenangkan, tapi meja TPS ini juga memiliki fungsi sebagai media pembelajaran khususnya untuk konsep dasar matematika penjumlahan, pengurangan, dan perkalian pada bilangan asli. Sempoa pada meja TPS sangat berguna dalam menanamkan konsep dasar penjumlahan, pengurangan dan perkalian dan tabel perkalian yaitu tabel perkalian batang Napier sebagai cara mudah menyelesaikan operasi perkalian bilangan besar jika telah memahami konsep dasar perkalian.

Dengan menggunakan meja TPS ini diharapkan dapat membantu Bimbel Quatum Education dalam menanamkan konsep-konsep dasar matematika penjumlahan, pengurangan, dan perkalian sehingga siswa dapat menerima dengan baik materi yang akan diberikan.

\section{METODE}

Program ini dilaksanakan di Bimbingan belajar Quatum Edcation, Jl. Swakarya/ Selada No.1, yang ditujukan untuk menunjang proses pembelajaran yang dilakukan oleh guru kepada siswa. Waktu pelaksanaan program ini adalah Maret 2019 sampai dengan Juli 2019. Meja TPS dibuat sesuai dengan ukuran meja pada umumnya. Setiap meja digunakan oleh satu siswa. Meja TPS ini menggunakan sistem buka tutup yang di dalam meja terdapat media sempoa (pada bagian dalam) dan tabel perkalian batang napier (pada bagian penutup). Perancangan Meja TPS dibuat melalui prosedur sebagai berikut.

1. Studi literatur 
Studi literatur berisikan serangkaian kegiatan pencarian dan pengkajian sumber sumber yang relevan dalam pengumpulan materi dan menjadi acuan dalam pembuatan Meja TPS ini. Literatur yang digunakan adalah buku-buku pelajaran sekolah dasar kelas 2 dan 3.

2. Pendesainan alat

Meja TPS didesain menggunakan photoshop guna mendapatkan hasil yang maksimal sesuai keinginan penulis dan Bimbingan belajar Quantum Education.

3. Penggumpulan alat dan bahan

Pendataan kebutuhan alat dan bahan sesuai tingkat kebutuhan. Pemilihan komponen ditinjau dari segi kualitas dan harga, sehingga bahan dan alat yang digunakan sesuai dengan alokasi dana yang diberikan.

4. Pembuatan alat

Pembuatan alat atau pembuatan Meja TPS sesuai dengan desain yang telah direncanakan. Oleh karena itu, untuk pembuatan Meja TPS, dilakukan kerjasama dengan salah satu pemilik usaha pengrajin kayu dengan nama "Paper Mart", "Pengetaman Kayu Ardhat Jaya" dan "Bengkel Las Mutiara Riau".

Setelah Meja TPS selesai dibuat sesuai dengan desain yang telah direncanakan, selanjutnya Meja TPS langsung diterapkan dan digunakan oleh tentor di Bimbingan belajar Quantum Education. Siswa yang akan menggunakan meja TPS ini merupakan siswa yang berada di kelas 2 dan 3 SD.

Pendampingan pembukuan usaha akan dilakukan setelah melihat keberhasilan dari Meja TPS dalam membantu pemberian pemahaman konsep dasar penjumlahan, pengurangan dan perkalian bilangan asli pada siswa kelas 2 s.d. 3 Bimbingan belajar Quantum Education. Keberhasilan dari Meja TPS ini dilihat dari hasil pretest dan posttest yang dikerjakan oleh siswa Bimbingan belajar Quantum Education.

Setelah kegiatan pendampingan pembukuan usaha dilakukan, tahap selanjutnya akan dilakukan kegaiatn mempromosikan bimbingan belajar Quantum Education melalui berbagai media masa. Promosi ini akan dilakukan setelah tim dan mitra melihat keberhasilan dari meja TPS dalam pembelajaran di bimbingan belajar Quantum
Education. Hal ini bertujuan untuk memberikan informasi bagi masyarakat bahwa bimbingan belajar Quantun Education memiliki inovasi baru berupa meja TPS yaitu meja yang dilengkapi sempoa dan tabel perkalian batang napier sebagai fasilitas meja dan media pembelajaran yang dapat meningkatkan pemahaman siswa dalam mempelajari konsep operasi hitung penjumlahan, pengurangan dan perkalian bilangan asli. Melalui promosi ini diharapkan akan membuka peluang besar bagi ketertarikan siswa untuk belajar di bimbingan belajar Quantum Education.

\section{HASIL DAN PEMBAHASAN}

Meja TPS dibuat sesuai dengan ukuran meja pada umumnya. Meja TPS digunakan oleh setiap siswa. Jadi, setiap siswa menggunakan satu meja. Meja TPS ini menggunakan sistem buka tutup yang di dalam meja terdapat media sempoa (pada bagian dalam) dan tabel perkalian batang napier (pada bagian penutup). Sempoa diletakkan berada di kiri sedangkan di bagian kanan adalah tempat kosong yang bisa digunakan siswa untuk menulis, hal ini dilakukan agar siswa tidak merasa sulit saat menulis ketika menggunakan sempoa maupun tabel perkalian.

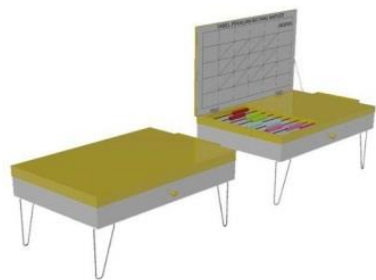

Gambar 1. Desain Meja TPS

Kemampuan pemahaman operasi hitung di Bimbingan belajar Quantum Education mengalami peningkatan setelah dilakukan kegiatan pembelajaran menggunakan Meja TPS. Hal ini dapat dilihat dari hasil pretest dan posttest yang diberikan pada 6 orang siswa Bimbingan belajar Quantum Education, yang menujukkan bahwa nilai siswa setelah menggunakan Meja TPS meningkat dari pada sebelum menggunakan Meja TPS, pengingkatan ini dapat dilihat pada gambar berikut. 


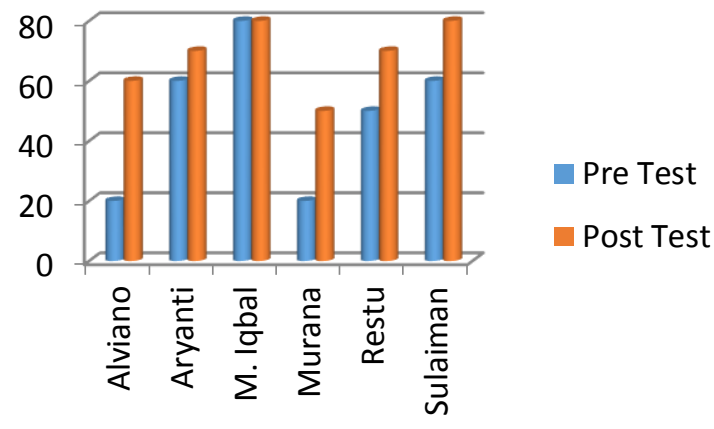

Gambar 2. Diagram Perbandingan Hasil Pretest dan Posttest

Meningkatnya nilai siswa ini sejalan dengan penelitian yang telah dilakukan Aristiani (2013) yang menunjukkan bahwa siswa mengalami peningkatan setelah menggunakan tabel perkalian batang napier. Hal ini terbukti dari data yang diperoleh saat intevensi pada pertemuan ke tujuh sampai kelima belas mencapai 90\%. Selain itu, peningkatan tersebut juga telah dibuktikan melalui analisis data estimasi kecenderungan arah, kecenderungan stabilitas, jejak data, level stabilitas, level perubahan. Selanjutnya, penelitian Romlah, dkk (2016) juga menunjukkan bahwa pelaksanaan kegiatan bermain sempoa dapat meningkatkan tiga aspek kemampuan berhitung secara signifikan. Hal ini terlihat dari hasil perhitungan t-test antar siklus, yang menunjukkan bahwa terdapat peningkatan kemampuan berhitung pada siklus I dan siklus II.

Berdasarkan penelitian yang telah dilakukan dan dari penelitian-penelitian sebelumnya, berarti penggunaan Meja TPS berhasil meningkatkan pemahaman pembelajaran siswa kelas 2 dan 3 SD. Selain itu, dengan menggunakan Meja TPS, kegiatan menjadi lebih menyenangkan dan siswa lebih mudah memahami materi hitung yang diberikan oleh guru. Meja TPS juga membantu meningkatkan kualitas fasilitas pada Bimbingan belajar Quantum Education yang sebelumnya hanya menggunakan meja kayu biasa. Desain Meja TPS yang unik dan berwarna cerah menarik minat dan memotivasi siswa dalam pembelajaran matematika.

Meja TPS dilengkapi dengan buku panduan berisikan cara penggunaan Meja TPS dan materi singkat mengenai penjumlahan, pengurangan dan perkalian pada bilangan asli. Melalui buku panduan, tentor dan siswa pada Bimbingan belajar Quantum Education akan terbantu dalam menggunakan Meja TPS.

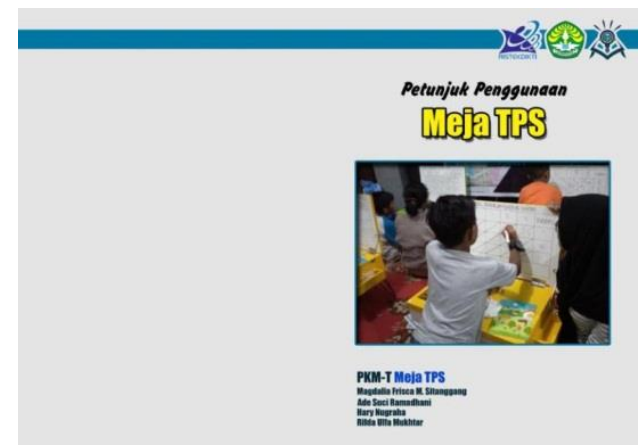

Gambar 3. Buku Panduan Meja TPS

Keberhasilan dari penggunaan Meja TPS dalam memberikan pemahaman konsep dasar penjumlahan, pengurangan dan perkalian pada bilangan asli juga memberikan keuntungan bagi Bimbingan belajar Quantum Education dari berbagai sisi. Keuntungan tersebut antara lain sebagai berikut.

1. Waktu proses belajar mengajar

Dengan menggunakan Meja TPS, pembelajaran dapat dilakukan lebih cepat. Sebelum menggunakan Meja TPS, Bimbingan belajar Quantum Education membutuhkan waktu 3 kali pertemuan dengan dengan durasi belajar setiap pertemuan masing-masing 2 jam. Setelah menggunakan Meja TPS, pemahaman siswa terhadap konsep operasi hitung penjumlahan, pengurangan dan perkalian dapat diperoleh lebih cepat, hanya membutuhkan waktu 1,5 jam.

2. Pengurangan Biaya Operasional

Dari hasil perbandingan pretest dan posttest kepada enam siswa Bimbel Quatum Education, penggunaan meja TPS pada jangka waktu panjang akan memberikan profit yang signifikan. Hal ini dapat dilihat dari penggurangan jam belajar yang akan menyebabkan pengurangan waktu tentor mengajar dan pengurangan penggunaan listrik.

Sebelum menggunakan meja TPS, Bimbel Quantum Education membutuhkan waktu tiga kali pertemuan dengan waktu dua jam 
setiap pertemuan. Dengan menggunakan meja TPS, pemahaman siswa terhadap konsep operasi hitung penjumlahan, pengurangan dan perkalian dapat dipahami lebih cepat sehingga hanya membutuhkan waktu 1,5 jam.

Pengurangan jam belajar setelah menggunakan Meja TPS menyebabkan penurunan biaya operasional yang dapat ditinjau dari penurunan pembayaran tentor untuk satu kelas dan pembayaran penggunaan listrik sehingga hal ini menyebabkan profit Bimbel Quantum Education mengalami peningkatan. Dengan biaya bimbingan belajar Rp280.000,00 perbulan. Penurunan biaya operasional Bimbel Quantum Education dapat dilihat pada Tabel berikut.

Tabel 1. Perbandingan Penggunaan Biaya Operasional

\begin{tabular}{|c|c|c|c|}
\hline $\begin{array}{l}\text { Penggunaa } \\
\text { n meja TPS }\end{array}$ & $\begin{array}{c}\text { Jenis } \\
\text { Operasional }\end{array}$ & $\begin{array}{l}\text { Biaya per } \\
\text { Pertemuan } \\
\quad(\text { Rp) }\end{array}$ & $\begin{array}{c}\text { Biaya per } \\
\text { Bulan / 12 } \\
\text { kali } \\
\text { Pertemuan } \\
(\mathbf{R p}) \\
\end{array}$ \\
\hline \multirow{3}{*}{ Sebelum } & $\begin{array}{l}\text { Honor } \\
\text { Tentor } \\
(2 \text { jam })\end{array}$ & 50.000 & 600.000 \\
\hline & $\begin{array}{l}\text { Biaya } \\
\text { Listrik } \\
\text { (2 jam) }\end{array}$ & 10.000 & 120.000 \\
\hline & \multicolumn{2}{|c|}{ Total } & 720.000 \\
\hline \multirow{3}{*}{ Sesudah } & $\begin{array}{l}\text { Honor } \\
\text { Tentor } \\
(1,5 \text { jam }) \\
\end{array}$ & 37.000 & 450.000 \\
\hline & $\begin{array}{l}\text { Biaya } \\
\text { Listrik } \\
(1,5 \text { jam })\end{array}$ & 7.500 & 90.000 \\
\hline & \multicolumn{2}{|c|}{ Total } & 540.000 \\
\hline
\end{tabular}

3. Peningkatan Pendapatan dan Jumlah Siswa

Pada tahun ajaran baru 2019/2020, jumlah siswa yang mendaftar di Bimbel Quantum Education mengalami peningkatan dari 2 tahun ajaran sebelumnya. Kenaikan jumlah siswa sekolah dasar Bimbingan belajar Quantum Education dapat dilihat pada grafik di bawah ini.

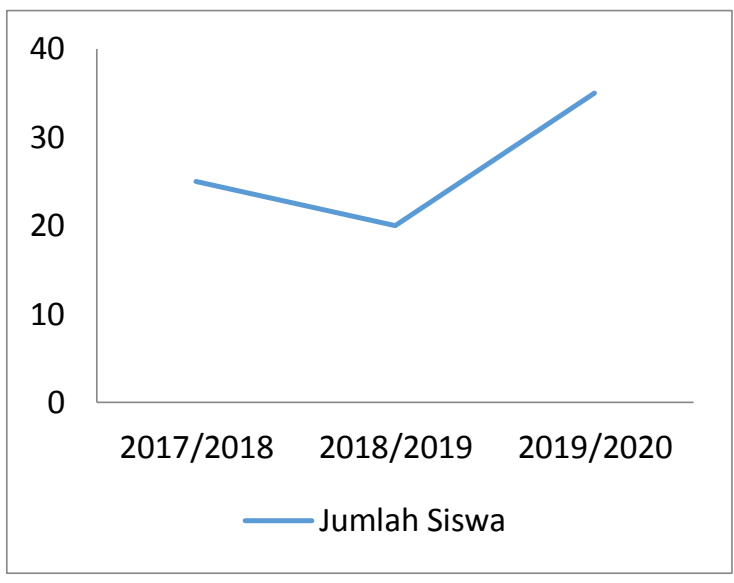

Gambar 4. Grafik Kenaikan Jumlah Siswa Bimbingan Belajar Quantum Education

Berdasarkan grafik tersebut, peningkatan jumlah siswa ini memberikan kenaikan pendapatan kotor setiap bulannya bagi bimbingan belajar dibandingkan tahuntahun ajaran sebelumnya. Hal ini dapat dilihat pada tabel berikut.

Tabel 2. Pendapatan Kotor Bimbingan Belajar Quantum Education

\begin{tabular}{|c|c|c|c|}
\hline $\begin{array}{l}\text { Tahun } \\
\text { Ajaran }\end{array}$ & $\begin{array}{l}\text { Jumlah } \\
\text { Siswa }\end{array}$ & $\begin{array}{c}\text { Pendapatan } \\
\text { per Bulan } \\
\text { (1 orang x } \\
300.000 \\
\text { dalam Juta } \\
\text { Rupiah) }\end{array}$ & $\begin{array}{c}\text { Pendapatan } \\
\text { per Tahun } \\
\text { (dalam Juta } \\
\text { Rupiah) }\end{array}$ \\
\hline $\begin{array}{r}2017 / \\
2018\end{array}$ & 25 & 7,5 & 90 \\
\hline $\begin{array}{r}2018 / \\
2019\end{array}$ & 20 & 6 & 72 \\
\hline $\begin{array}{r}2019 / \\
2020\end{array}$ & 33 & 9,9 & 118,8 \\
\hline
\end{tabular}

Meningkatnya jumlah siswa juga memberi peluang kepada tentor untuk mengajar lebih dari satu kelas, sehingga penghasilan keseluruhan tentor setiap bulannya akan mengalami peningkatan setelah menggunakan Meja TPS yaitu sebesar Rp.1.200.000 sehingga manfaat dari Meja TPS tidak hanya dirasakan oleh Bimbingan belajar Quantum Education tetapi juga dirasakan oleh tentor. 


\section{SIMPULAN}

Dari kegiatan yang telah kami lakukan di bimbingan belajar Quantum Education, maka dapat disimpulkan bahwa Penggunaan Meja TPS atau Meja Tabel Perkalian dan Sempoa berhasil mengatasi permasalahan pada bimbingan belajar Quantum Education mengenai kurangnya pemahaman siswa bimbingan belajar terhadap konsep dasar penjumlahan, pengurangan dan perkalian pada bilangan asli. Dengan Meja TPS, pemahaman siswa dapat meningkat, pembelajaran lebih menyenangkan sehingga menimbulkan ketertarikan dan motivasi siswa dalam belajar. Hal ini dapat dilihat melalui hasil pretest dan postest siswa Bimbingan belajar Quantum Education.

Meja TPS yang didesain dengan warna yang menarik dan yang cerah, baik warna sempoa dan warna meja, membuat pembelajaran lebih menyenangkan dan memotivasi siwa untuk belajar matematika. Bahan yang berkualitas tinggi dan awet, menjadikan Meja TPS menjadi fasilitas terbaru dan berkualitas pada Bimbingan belajar Quantum Education.

Keberhasilan dari penggunaan Meja TPS meningkatkan ketertarikan masyarakat sehingga siswa yang belajar di Bimbingan belajar Quantum Education untuk tahun ajuran baru 2019/2020 mengalami peningkatan. Hal ini menyebabkan kenaikan profit pada Bimbingan belajar Quantum Education.

\section{DAFTAR PUSTAKA}

Aristiani, N. (2013). Penggunaan Media Batang Napier Dalam Meningkatkan Kemampuan Operasi Perkalian Bagi Anak Kesulitan Belajar Kelas 3 Sd 11 Belakang Tangsi Padang. Jurnal Ilmiah Pendidikan Khusus, 1(1), 294-310.
Juliant, A dan Noviartati K. (2016). Analisis Kesalahan Siswa dalam Menyelesaikan Soal pada Materi Pola Bilangan Ditinjau dari Kemampuan Matematika Siswa. Jurnal Riset Pendidikan, 2(2), 111-118.

Rusli, R. A. (2018). Komparasi Pembelajaran Kooperatif Tipe STAD dan Pengajaran Langsung dengan Pemberian Scaffolding dalam Pembelajaran Matematika Siswa Kelas VII SMP Negeri 33 Makassar. Universitas Negeri Makassar: Tesis

Romlah, M., Kurniah, N., dan Wembrayarli. (2016). Peningkatan Kemampuan Berhitung Anak Melalui Kegiatan Bermain Sempoa. Jurnal Ilmiah Potensia, 1(2), 72-77.

Shufa, N. K. F. (2016). Studi Implementasi Pemanfaatan Media Pembelajaran IPA Kelas V di SDN Kecamatan Mijen Kota Semarang. Universitas Negeri Semarang: Tesis

Siagian, M D. (2016). Kemampuan Koneksi Matematika dalam Pembelajaran Matematika. MES (Journal of Mathematics Education and Science), 2(1), 58-67.

Syifa, F. M dan Simatupang, N.D. (2015). Penggunaan Sempoa Dalam Pengembangan Kemampuan Berhitung Permulaan Anak. Jurnal UNESA, 4(2), 16 